\title{
On the of neural modeling of some dynamic parameters of earthquakes and fire safety in high-rise construction
}

\author{
Larisa Haritonova ${ }^{1, *}$ \\ ${ }^{1}$ Volgograd State Technical University, 400005, Volgograd, Lenin Avenue, 28, Russia
}

\begin{abstract}
The recent change in the correlation of the number of man-made and natural catastrophes is presented in the paper. Some recommendations are proposed to increase the firefighting efficiency in the high-rise buildings. The article analyzes the methodology of modeling seismic effects. The prospectivity of applying the neural modeling and artificial neural networks to analyze a such dynamic parameters of the earthquake foci as the value of dislocation (or the average rupture slip) is shown. The following two input signals were used: the power class and the number of earthquakes. The regression analysis has been carried out for the predicted results and the target outputs. The equations of the regression for the outputs and target are presented in the work as well as the correlation coefficients in training, validation, testing, and the total (All) for the network structure 2-5-5-1 for the average rupture slip. The application of the results obtained in the article for the seismic design for the newly constructed buildings and structures and the given recommendations will provide the additional protection from fire and earthquake risks, reduction of their negative economic and environmental consequences.
\end{abstract}

\section{Introduction}

On of the construction priorities in the world today is the high-rise construction in big cities. It is explained by the lack of vacant territories OR their high price. The high-rise construction boom in Russia is yet to come. The high-rise buildings' construction in cities or in the country enhances their status unofficially. However, it requires to secure safe functioning processes in these structures. The UNO data shows that by the number of those who suffered or were killed among various modern day catastrophes, the first place is taken by hydrometeorological disasters (tsunami, floods, etc.), the second place take the geological ones (volcanic eruptions, earthquakes, etc.), the third place is taken by man-made disasters. In which case, in recent years we can observe the regularity of increasing number of man-made disasters at the simultaneous increasing of the natural calamities [1]. More than half of the accidents registered by the Major Accidents Reporting System MARS (functioning under the authority of the European Committee - Italy) at the United Research Center were caused by the following factors: inefficiency of monitoring the environment safety systems and the low

* Corresponding author: haritonova410@yandex.ru 
level of occupational safety [2]. The high-rise structures have a higher degree of potential danger in comparison with the common ones. Fires in these buildings can result in more injured people and material damage. The firefighting is hampered by the structure height, difficulties in fire extinguishing instruments delivery to the fire outbreak level and hydrometeorological conditions, for instance, strong wind speed fluctuations that usually increases with the building's height [3-5].

Along with the climatic conditions, the fire situation in the high-rise buildings is influenced also by social factors; part of them is given in the paper [5]. The article [4] analyzes fires in high-rise buildings in the Russian Federation and abroad, and the recommendations are given to increase the efficiency of firefighting systems. Some critical factors are shown for high-rise buildings:

-the blocking of escape routes inside the structure;

-difficulties in the supply of firefighting means and rescue efforts;

- a very rapid smoke and fire spread.

The fire consequences in high-rise buildings over the recent five years are analyzed in the article [6]. It is stated that in fire guard garrisons of the Russian Emergency Ministry (especially in the provinces but not in the capitals), there are often no life saving equipment in the high-rise buildings. And even if there are some cranked elevators or rung ladders, the firefighting brigades cannot quickly find a place for regrouping or even simply to install the needed rescue equipment. The work [7] shows some means of warning and controlling the fire evacuation which function on the basis of the network technologies. The solution of the firefighting problem is often seen in providing the fire brigades with very expensive turntable ladders and elevators [4]. However, their exploitation is not always effective at the building's height of more than 60 meters.

\section{Recommendations on the enhancement of fire extinguishing efficiency in the high-rise building}

The number of fire safety rules failures increases significantly over a large time period of using high-rise buildings. For example, the fire-alarm and systems of smoke removal get out of order (resulting from an improper use). Very often, the trapdoors between the outer ladders stairways are blocked or there are no means of individual protection.

It seems advisable -to cut the circle radius of fire stations;

-to equip the high-rise buildings with special elevators (not less than one for a fire compartment) for moving fire platoons;

-it is extremely important to foresee zones with the increased fire resistance period and equipped with fire cranes;

-to use high fire resistance materials in construction and finishing the high-rise buildings.

It is less expensive but efficient, to rehearse periodically after the appropriate training with the residents or staff members working in the high-rise structures. It is also an effective the installation of video observation systems and the fire extinguishing systems that can work automatically.

\section{Use of the neural simulation method for some dynamic parameters of earthquake sources}

The urbanization of territories put forward demands to securing the reliability of buildings and structures in order to reduce the risk of living in seismic danger regions. This is especially important due to the fact that we can observe the process of global seismic activization. 
Under these circumstances, if in the years 2003-2006 the number of man-made catastrophes exceeded those of natural origin by several times, already in the years 2007 2010 the number of natural disasters significantly exceeded the man-made ones(by several times) [1]. A very intensive construction of high-rise buildings and structures is being observed today not only in big cities but also on the south coast of Crimea which is a seismically dangerous area. The seismic activities of magnitude up to 9 are observed here. Nowadays, the various methods of simulating processes are widely spread [8-17].

When designing and constructing high-rise buildings, it is insufficient to study results of only macro-seismic activity for predicting the possible seismic impact [18-20].

The paper [18] obtained the equations of connections (empirical dependences) with the help of the orthogonal regression method by the average interval values for various dynamic parameters of earthquake sources upon an energetic class. These dependences which this work calls "long-term ones" were obtained by the data of analog seismic recording systems as a result of generalization of 512 pairs of dynamic parameters in the Crimean earthquake sources within the years 1955-2007.

The author has compared the graphically presented above-mentioned empirical dependences with the values of dynamic parameters determined by the data obtained at the digital seismic stations. This comparison showed that the value of the U parameter (the dislocation value(or the average rupture slip) found from the determining the seismic moment (the power characteristic of the earthquake source) by the data of the digital seismic stations were lower in general than were assumed by the long-term dependences (by 1/5 order of magnitude). Therefore, the given article proposes to simulate some dynamic parameters with the help of the Neural Network simulation. Were use the statistic data [18] for the average earthquake dynamic parameter analysis at the foci of 58 Crimean earthquakes in the years 2007-2011. These data are restored by the 306 amplitude spectrums of the digital seismic stations' records.

The neural network architecture included the two nodes in the input layer. The following two input signals were used: the power class $K_{\Pi}$ and the number of earthquakes $N$. With the two input variables and two hidden layers, the number of neurons in each of the hidden layers will be taken as $1 ; 2 ; 4 ; 5$. Let us take the network structures in the form: $(2-5-5-1)$. The Uparameter, the dislocation value (or average rupture slip) was taken as the target data. A $2 \mathrm{x}$ 58 - matrix was utilized. The Levenberg-Marquardt algorithm has been chosen for the network training in this study. As the Performance function - the Mean Squared Error was used. As the transfer function, the hyperbolic tangent was applied.

\section{Results}

The neural model geometry and some applied algorithms are given in Fig. 1, and some results of the experiments are shown in Fig. 2-3.

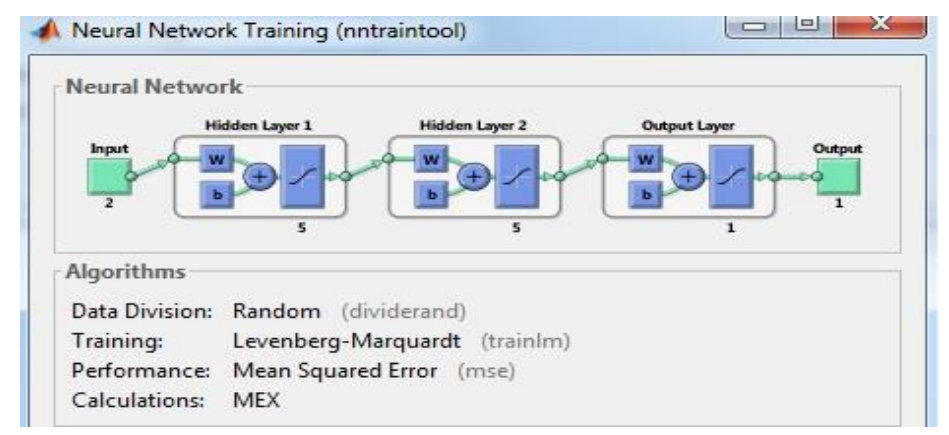

Fig. 1. The example of the network structure 2-5-5-1 and algorithms. 


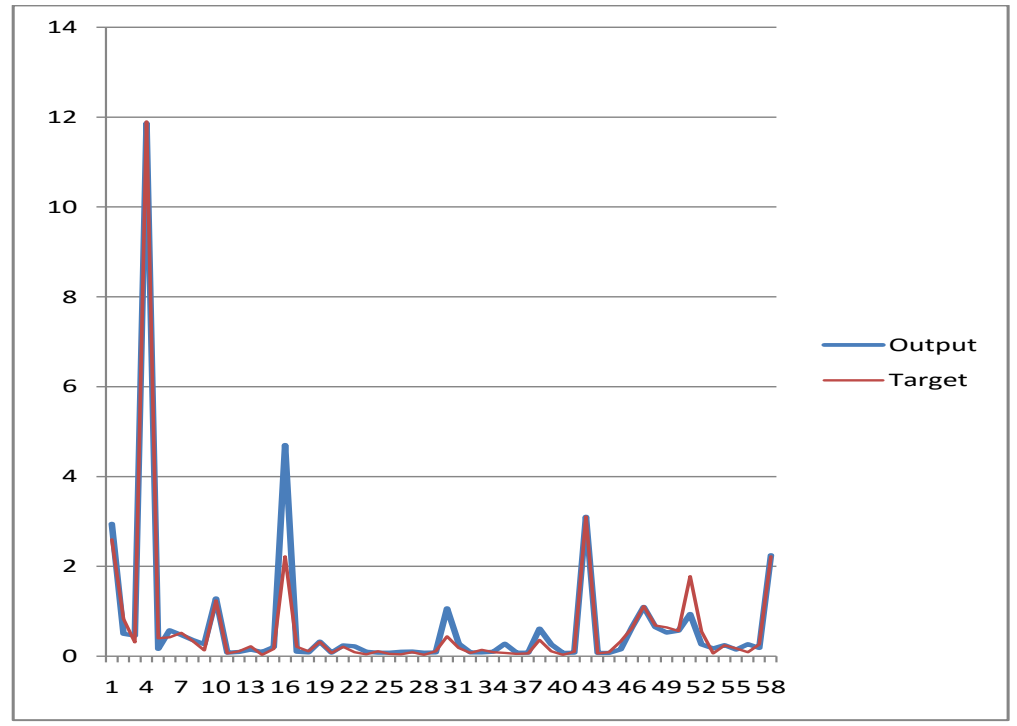

Fig. 2. The graph of the comparison target data for the average rupture slip from the publication [18]) with the output values (calculated with the help of neural network) for the network structure 2-5-5-1.

The equations of the regression obtained in this study for the outputs and target, and the correlation coefficients in training, validation, testing, and the total (All) for the network structure 2-5-5-1 for the average rupture slip are presented in Fig.3.

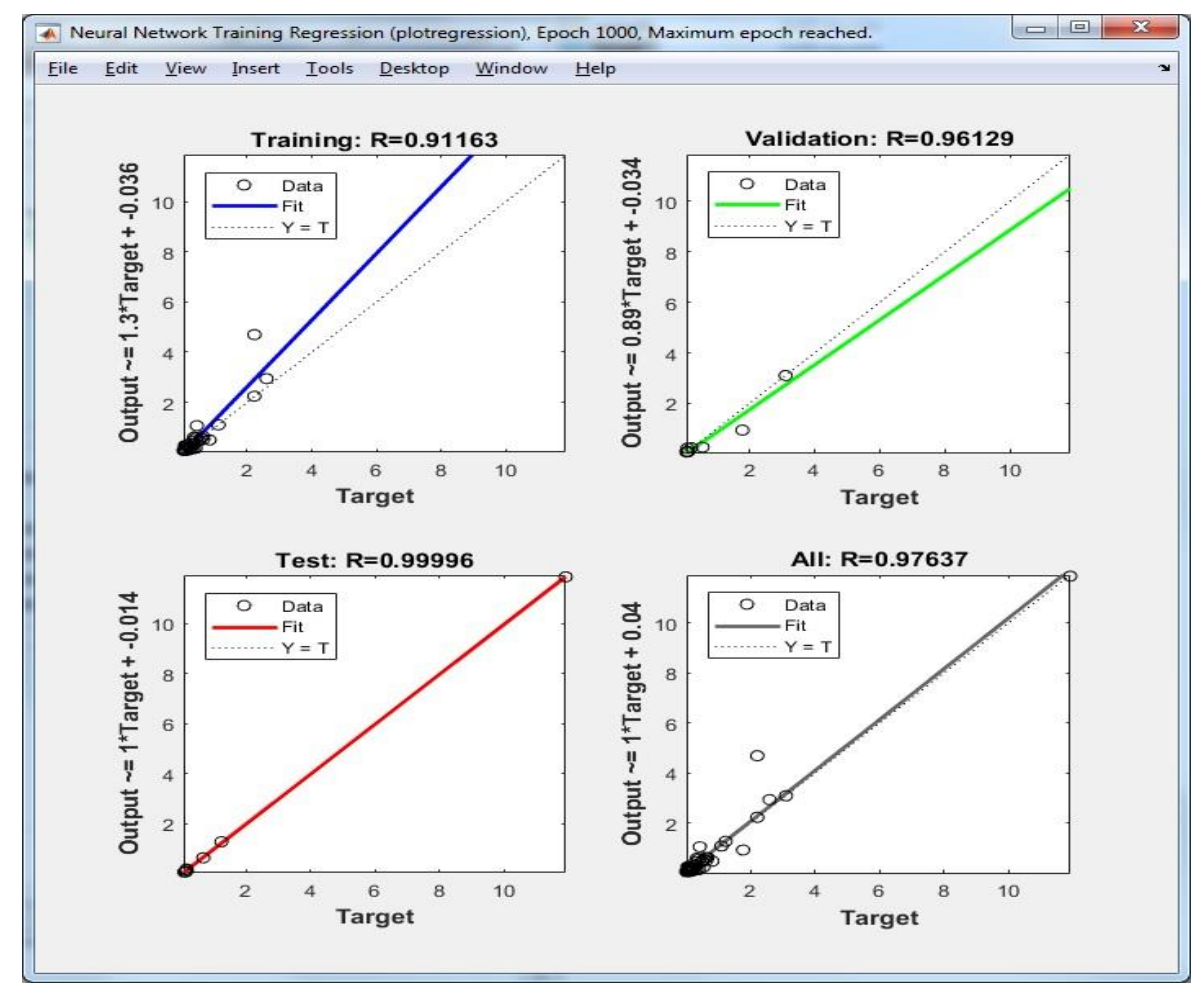

Fig. 3. Equations for the target outputs, target and correlation coefficients in training, validation, testing, and the total (All) for the network structure 2-5-5-1 for the average rupture slip. 
The comparison target data for the average rupture slip from the publication [18]) with the output values (calculated with the help of neural network) for the network structure 2-5-5-1 (the graph 2) show a good agreement.

\section{Conclusions}

In the future it is supposed to continue the study of using the neural network modeling for other dynamic parameters of earthquakes foci to solve practical problems in the engineering seismology. The application of the obtained results in the seismic design for the plotted and constructed buildings and structures as well as the presented recommendations will result in the additional protection from possible fire and earthquake risks, the reduction of their negative environmental and economic consequences.

\section{References}

1. Y.V. Sychev, Internet Zhurnal Tekhnologii Tekhnosfernoy Bezopasnosti, 1 (41) (2012)

2. W.G.Garrison, Large property damage losses in the hydrocarbon-chemical industries. A thirty-year review (New York, 1998)

3. E.E. Kirukhancev, V.N. Ivanov, Internet Zhurnal Tekhnologii Tekhnosfernoy Bezopasnosti, 4(50) (2013)

4. E.E. Kirukhancev, V.N. Ivanov, Internet Zhurnal Tekhnologii Tekhnosfernoy Bezopasnosti, 5(51) (2013)

5. Tien Minh Nguyen, E.E. Kiryukhantsev, Internet Zhurnal Tekhnologii Tekhnosfernoy Bezopasnosti, 2 (72) (2017)

6. S.V. Sharhuv, Technospere Safety, 4 (9), 37- 42 (2017)

7. S.V. Sharhun, Journal «Pozharovzryvobezopasnost. 22(2), 60-64 (2013)

8. L. Haritonova, Advances in Intelligent Systems and Computing. Springer, Cham., 692 (2018)

9. L. Haritonova, Procedia Engineering, 206, 1002-1008 (2017)

10. L.P. Haritonova, International Scientific and Practical Conf. World science, 8 (12), 47 55 (2016)

11. L.P. Haritonova, MATEC Web Conf. 106, 06006 (2017)

12. L.P. Haritonova, International research journal, 8-3(50), 155-158 (2016)

13. L.P. Haritonova, Proceedings of the Second International Scientific and Practical Conferences "The Top Actual Researches in Modern Science (28-29 July 2016 Ajman $U A E)$ " International Periodical Scientific Edition: International Scientific and Practical Conferences "World science", 8 (12), (2016)

14. S.V. Novikova, Neural network simulation for solving the monitoring problems under conditions of incomplete fuzzy information (by an example of ecological monitoring) (DrSc thesis, Kazan State Technical University) (2013)

15. L.P. Haritonova, Int. Sci. J. (ISJ) Theor. Appl. Sci. 34(2), 164-171 (2016)

16. L.P. Haritonova, International research journal, 3(45), P 2 91-93 (2016)

17. L.P. Haritonova, Intern. periodical scientific edition: Intern. Sci. and Practical Conf. World science (Proc. of the II Intern. Scientific and Practical Conf. "Modern Scientific Achievements and Their Practical Application (Dubai UAE)"), 3 (3), $54-56$ (2015) 
18. B.G. Pustovitenko, E. A. Merger, A. A. Pustovitenko, Geofizicheskiy Zhurnal, 35 (5), 172-186 (2013)

19. B.G. Pustovitenko, E. A. Merger, Geodynamics, 1 (14), 124-128 (2013)

20. B.G. Pustovitenko, V.E. Kulchitskiy, I.V. Kalinyuk, E.A. Merger, Seismostoykoye stroitelstvo. Bezopasnost sooruzheniy, 6, 20-23 (2012) 